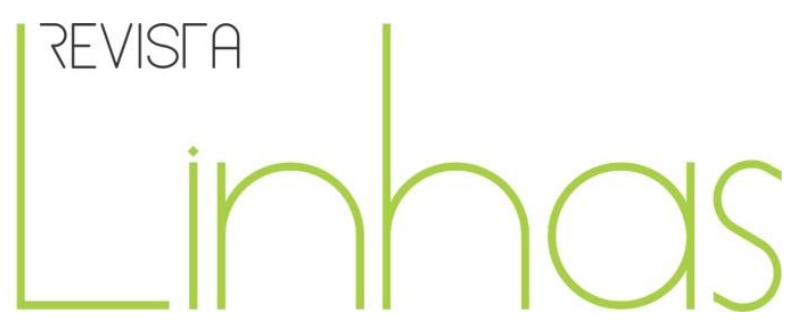

\title{
Resenha do livro "Pierre Bourdieu: uma sociologia ambiciosa da educação"
}

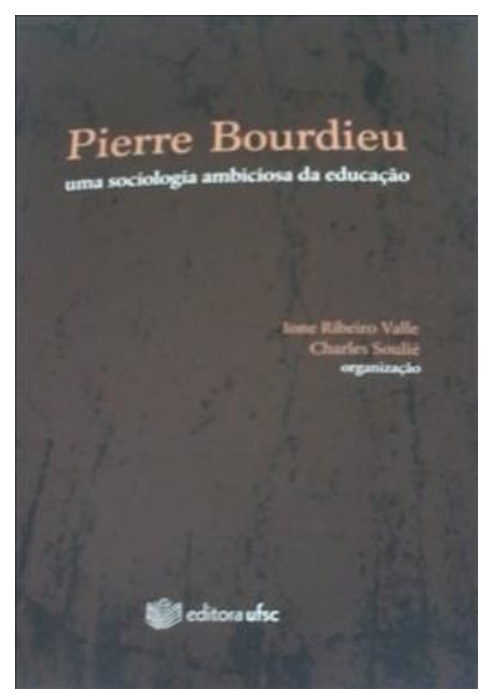

VALLE, Ione Ribeiro; SOULIÉ, Charles (Orgs.). Pierre Bourdieu: uma sociologia ambiciosa da educação. Florianópolis: Editora da UFSC, 2019, 381p.

\section{Cristiano Mezzaroba}

Universidade Federal de Sergipe - UFS - Brasil cristiano_mezzaroba@yahoo.com.br

\section{Para citar esta resenha:}

MEZZAROBA, Cristiano. Resenha do livro "Pierre Bourdieu: uma sociologia ambiciosa da educação". Revista Linhas. Florianópolis, v. 21, n. 45, p. 404-411, jan./abr. 2020. 
Apresentar Pierre Bourdieu talvez seja desnecessário, porque certamente é um dos sociólogos contemporâneos com grande contribuição às Ciências Sociais e Humanas, bem como à Educação. Passados, já, dezessete anos de sua morte, a candência de suas reflexões e produções quando articuladas às questões atuais é inequívoca. Nos textos aqui traduzidos, organizados por Ione Ribeiro Valle e Charles Soulié, evidenciam-se os elementos de um autor que permanece importante e intrigante, e é por isso que o pensamento bourdieusiano poderia ser encaixado naquilo que denominamos de “clássicos” do pensamento sociológico e pedagógico: porque embora formulado em outro momento histórico, sua "miscelânea sociológica” permanece atual e presente nas análises que hoje realizamos para entender a complexidade do nosso tempo presente, e também porque sua escola, como escrevem os organizadores desta obra, "foi primeiramente uma formidável escola de liberdade intelectual” que segue influenciando novas gerações de estudantes e pesquisadores. O livro está organizado em treze seções, entre listas, textos, anexos, índice remissivo e a apresentação dos organizadores e tradutores. A partir do prefácio, em que os organizadores contextualizam quanto ao sociólogo e a potência de sua obra em relação à educação e à política, temos na sequência oito textos (com textos próprios de Bourdieu, outros com coautorias diversas, uma entrevista e uma conferência), os quais foram publicados dispersamente, em revistas francesas (como a Actes de la recherche en sciences sociales - criada pelo próprio Bourdieu em 1975), jornais e portfólios, no período compreendido entre 1968 e 2000.

O prefácio - A centralidade da relação entre educação e política em Pierre Bourdieu dedica-se, primeiramente, a explicitar aspectos biográficos de Bourdieu "colados" ao seu contexto sócio-histórico (sua origem social, sua ascensão escolar, seus deslocamentos pela França, a experiência na Argélia, a conversão da filosofia para a etnologia e depois para a sociologia - essa retrospectiva nos leva à indagação: seria a sociologia constituída pela auto-análise?). O primeiro texto traduzido intitula-se $O$ exame de uma ilusão, que tem parceria de Jean-Claude Passeron, tendo sido publicado originalmente na Revue française de sociologie em 1968 e contém, com o rigor e critério comum às reflexões e análises bourdieusianas, o desvelamento do exame no sistema de ensino francês, pois, conforme os autores, os exames têm um efeito de ocultar as funções do sistema escolar, como se 
este fosse o (único) responsável pela exclusão e seleção, desconsiderando o pertencimento às classes sociais.

Os sistemas de exames são regulatórios, com a ilusão da neutralidade e da independência do sistema escolar em relação às classes sociais, "explicando" os erros e êxitos no sistema escolar/universitário e justificando porque alguns encontram barreiras "naturais" na sua trajetória educacional, enquanto para outros há maior facilidade em ascender socialmente via sistema de ensino. Bourdieu e Passeron captam e desvendam essa "tendência" atual nas sociedades industriais que multiplicam os exames, dando-lhes um grande peso no interior de seus sistemas de educação, sendo a escola essa instituição encarregada pela conservação e transmissão da cultura de uma dada sociedade (e pela capacidade da escola em transmutar vantagens sociais em vantagens escolares reconversíveis em vantagens sociais).

No caso francês, eles consideram que há um “frenesi francês da classificação”, pela incessante e intensa característica da França em hierarquizar e com isso "garantir" o lugar de cada um (de acordo com sua origem de classe) na sociedade. Para Bourdieu e Passeron, seguindo a lógica de pensamento já presente na obra Os herdeiros, as classes sociais são vítimas da autoeliminação, imediata ou diferenciada, ao invés do fracasso nos exames, isto é, o fenômeno que determina o lugar/papel de cada um é anterior ao "exame" ou ao “concurso", ele é determinado pelo pertencimento a uma determinada classe social, na maneira como se acessa a escola, se adere às suas normas e se tem ou não sucesso nela, bem como ao capital cultural transmitido pela família.

No segundo e mais longo texto da compilação, Provação escolar e consagração social: as classes preparatórias para as Grandes Escolas, publicado em 1981 na Actes de la recherche en sciences sociales, Bourdieu relata o contexto de uma pesquisa que, em sua essência, procurou romper com as evidências em relação à "mágica social da consagração", ou seja, novamente temos a tipologia de desvelamento praticada à exaustão pelo sociólogo em tela, a partir do exercício de compreensão de um campo social (a escola, a universidade) e a inculcação de disposições (habitus) em seus agentes, nos quais é possível observar os "jogos” (a illusio em Bourdieu), com vistas à distinção. A sociologia, para Bourdieu, utilizando-se de métodos de pesquisa diversos e comparativos, deve servir para desvelar as evidências da realidade e revelar os mecanismos de distinção. 
Neste longo texto, Bourdieu se propõe a compreender - e denunciar - que os efeitos técnicos da ação simbólica da educação, entendidos como "atos de consagração", em específico quanto às classes preparatórias para as Grandes Escolas francesas, já são definidores do sucesso escolar e formativo (ele chama de "socialização antecipada"), porque são instituições detentoras de um habitus distintivo (o métier) das classes dominantes que procuram garantir aos seus "herdeiros" posições de destaque para permanecerem (conservarem-se) na elite da sociedade - seria, segundo sua denominação, o que se configura como "dialética da consagração e do reconhecimento".

O terceiro texto evidencia as contribuições de Bourdieu à Sociologia da Educação, a partir de um texto prospectivo, diante do sempre realista e "desvelador" Pierre Bourdieu. Embora tenha sido desconsiderado pelo governo francês, que solicitou o documento, vemos nos escritos elementos que se configuram como esperançosos, inclusive em nosso momento presente, quando pensamos em melhorias no sistema educacional. Trata-se do texto Proposições para o ensino do futuro: Relatório do Collège de France (1985), publicado inicialmente em 1985, em Éditions de Minuit e, posteriormente em Le Monde de l'Éducation. São propostos nove princípios ${ }^{1}$ diante da necessidade de se repensar o sistema de ensino francês, considerando-se os avanços da ciência, as transformações econômicas e sociais, as inovações tecnológicas e o desenvolvimento dos meios de comunicação, e, claro, as transformações do próprio sistema de ensino. O objetivo dessas melhorias seria trazer a juventude - e as melhores mentes - para o campo pedagógico, mas, como o próprio Bourdieu se questiona, não podemos nos esquecer que "um discurso bem-intencionado não é suficiente para produzir o melhor dos mundos escolares possíveis". Embora o sociólogo constate, naquele momento, o poder (e as possibilidades) da televisão, do videocassete, das antenas parabólicas, é inegável que a transposição histórica de seus princípios, atualizando para nossas tecnologias atuais (principalmente em relação às possibilidades com a internet e as tecnologias digitais de informação e comunicação) ainda se mantém como atual e prospectivo.

\footnotetext{
${ }^{1}$ I - A unidade da ciência e a pluralidade das culturas; II - A diversificação das formas de excelência; III - A multiplicação das oportunidades; IV - A unidade no e pelo pluralismo; $\mathrm{V}$ - A revisão periódica dos saberes ensinados; VI - A unificação dos saberes transmitidos; VII - Uma educação ininterrupta e alternada; VIII - O uso das técnicas modernas de difusão; IX - A abertura na e pela autonomia.
} 
O texto que segue, intitulado Princípios para uma reflexão sobre os conteúdos do ensino. Relatório Bourdieu-Gros (1989), configura-se como um portfólio distribuído aos professores em 1989. Nele, temos sete princípios² propostos por Bourdieu e François-Gros que compunham, em 1988, uma comissão, presidida pelos dois, para refletir sobre os conteúdos de ensino do sistema francês, solicitado por Lionel Jospin, então Ministro da Educação Nacional. A proposta do documento não tinha intenção de intervir de maneira direta e em curto prazo, mas orientar uma transformação progressiva dos conteúdos, considerando a evolução da ciência e da sociedade e também aquilo que deve seguir tendo sua perpetuação histórica e sua adaptação necessária ao futuro. Embora o texto seja notável, teve pouca influência sobre a lei francesa que reorientou o ensino francês em 1989 e desencadeou estratégias que procuraram garantir o fracasso do documento elaborado.

No quinto texto, Para que serve o sociólogo?, temos algumas colocações proferidas por Bourdieu em um encontro com professores primários de sua circunscrição, organizado por Ronald Klapka, em 1983. A parte inicial é constituída pelo modo particular com que Bourdieu desenvolve uma tentativa de compreensão sobre a ciência que ele mesmo faz, ou seja, a Sociologia, em relação também à Pedagogia, considerando-se, naquele momento, seu público interlocutor. Percebe-se, visivelmente, que a própria conferência pedagógica em que Bourdieu estava em ação é concebida como um fato social, pela responsabilidade com que ele se coloca diante de seu público (por ser um "ato político") e também no modo como procura elencar elementos e propriedades da Sociologia. $O$ exercício realizado por ele é o de "permitir saber um pouco melhor o que se faz, o que se é", e isso, conforme suas ideias, deveria ser uma operação para qualquer agente que se dedica ao campo em que atuará, pois uma das propriedades da sociologia - e do ofício do sociólogo - é analisar o que se faz, nos contextos sociais particulares, bem como, realizar o exercício da dúvida, reconhecendo que a dúvida está presente e constituiu a produção dos saberes sociológicos. Para Bourdieu, ao se compreender o que se faz, já se permite

\footnotetext{
${ }^{2}$ De maneira resumida, os princípios foram: (1) Avaliação e atualização constante dos programas devido aos progressos da ciência e às mudanças da sociedade; (2) A educação deve privilegiar e garantir que todos os ensinos sejam apropriados, oferecendo modos de pensamento com validade e aplicabilidade gerais; (3) Os programas devem ser abertos, flexíveis, passíveis de revisão, progressivos e coerentes; (4) O exame crítico dos conteúdos exigidos deve sempre conciliar a sua exigibilidade e sua transmissibilidade; (5) Preocupação maior com a quantidade dos saberes realmente assimilados ao invés da quantidade dos saberes teoricamente propostos, distinguindo o que é obrigatório, opcional ou facultativo em relação ao saberes ensinados; (6) Coerência entre os ensinos ministrados em comum por professores de diferentes especialidades; (7) Garantir a excelência do ensino considerando-se a busca do equilíbrio e a integração entre as diferentes disciplinas.
} 
resolver um bom número de questões do próprio campo. Ainda, a Sociologia possui uma perspectiva de formulação de leis sociais referentes ao funcionamento social do mundo, como ele mesmo fez a partir de suas categorias conceituais como capital cultural, capital econômico e habitus, presentes claramente em sua exposição. Conhecendo as leis sociais será possível a transformação do mundo social.

O tema da dominação aparece no sexto texto da coletânea. Trata-se de uma conferência proferida por Bourdieu na Universidade de Rouen, em 26 de novembro de 1997, cuja temática foi A dominação. Nele, Bourdieu aciona autores clássicos (como Hume, Hobbes, Weber, Elias, Freud, Foucault, Nietzsche e Marcuse) para refletir e analisar a questão do por que obedecemos, ou seja, a questão do poder, não no sentido de sentirmos a coerção física e direta do Estado, mas em relação à forma como nos sujeitamos, na crença que passamos a ter quanto ao poder das instituições (e na obediência a esses códigos). Ele mostra, com sua erudição, que o poder simbólico se configura como uma problemática paradoxal e ao mesmo tempo surpreendente, porque através dele o dominado colabora com sua dominação. Para ilustrar isso, novamente Bourdieu aciona seus conceitos de campo (mostrando como as diferentes instituições funcionam sempre à base das disputas, das oposições e subordinações) e de habitus (argumentando que há uma herança de um sistema de disposições que, embora constituintes de subjetividades, práticas e estratégias, não podem ser pensadas como eternas e imutáveis), trazendo exemplos como a dominação masculina, a dominação entre etnias e entre classes, além de outras formas. A dominação, segundo Bourdieu, refere-se à articulação entre a origem social e ao pertencimento a determinada classe social, envolvendo elementos importantes como o capital cultural e escolar.

Os escritos de Pierre Bourdieu, Olivier Christin e Pierre-Étienne Will, publicados no ano de 2000 na revista Actes de la recherche en sciences sociales, com o título Sobre a ciência do Estado, é o sétimo e penúltimo texto traduzido da obra e retoma rapidamente algumas ideias centrais daqueles considerados como os principais responsáveis por pensar e sistematizar aquilo que constituiu o Estado moderno. A perspectiva é de sugerir uma interpretação interdisciplinar, envolvendo a história e a sociologia, fugindo de certas ilusões historiográficas, como por exemplo, visões que consideram o Estado num processo constante de "modernização", de "racionalização" e de "secularização", desconsiderando 
a participação e decisões dos agentes históricos nesses processos todos. Para esses autores, o Estado-Nação não é a forma acabada da história do Estado, e entender tal contexto só será possível utilizando-se - que é o que eles sugerem - uma perspectiva comparativa e interdisciplinar (por isso vemos exemplos entre China e Europa no texto, e a maneira como cada um desses lugares criou/sistematizou suas políticas de bem estar social, a partir da demografia, da estatística e da economia política). Visualiza-se também no texto uma breve discussão sobre a questão da burocratização dos Estados, a qual é tratada sob a ótica de Max Weber, ou seja, essa necessidade inerente dos Estados modernos (europeus) em criarem um controle interno extremo, o que passa a ser seu próprio fundamento.

Seguindo as reflexões quanto ao ofício do sociólogo e indagando quanto ao papel da Sociologia no universo científico e social, no texto que fecha a coletânea, Uma entrevista com Pierre Bourdieu: "É preciso reinventar uma espécie de intelectual coletivo tendo como modelo os Enciclopedistas", temos a conversa do sociólogo com Franck Nouchi, publicada no jornal Le Monde, no dia 07 de dezembro de 1993. A entrevista, basicamente, trata do campo científico e considera a sociologia como a última ciência inventada no bojo das discussões epistemológicas. Nela, Bourdieu deixa claro que há um certo número de propriedades que permitem a essa ciência ser classificada entre as ciências, pela sua tentativa de construção de modelos explicativos, confrontados à experiência (pela observação, enquete estatística e também pelo método comparativo).

Bourdieu, oportunamente, aproveita-se da entrevista para demarcar características da Sociologia em meio às demais ciências, em especial, a exigência da reflexividade na construção de suas pesquisas e explicitar que a Sociologia não pode ser entendida como uma ciência neutra porque está permanentemente "contaminada" com a realidade social, a qual deve ser desvelada pelo pesquisador nos seus intentos investigativos. O sociólogo, para Bourdieu, é alguém que está preso ao seu objeto, por isso a suspeição que se tem dos agentes deste campo diante de suas posições quanto aos objetos sociais. As suas explicações quanto ao campo científico são muito claras e permitem ao leitor entender um pouco mais essa constante tensão e luta (nas palavras do próprio autor, "um jogo" - e aqui poderíamos pensar obviamente na illusio como forma estratégica de participar desse “jogo” -, que é inventado pouco a pouco) que é a base das explicações quanto ao conceito 
bourdieusiano de campo (científico, político, econômico, jurídico, jornalístico, esportivo, artístico etc.).

Na sequência o livro ainda traz um quadro comparativo dos sistemas de ensino entre Brasil e França, para compreendermos essas particularidades e diferenças, além do índice remissivo e da seção sobre os organizadores e tradutores.

Como podemos constatar, escritos dispersos, publicados, alguns, há mais de 40 anos, mas com uma "força” crítica e reflexiva que contribuíram para a formação do campo sociológico no mundo todo e que agora, com os textos traduzidos para a língua portuguesa, permitirão àqueles que fazem uso desta linguagem melhor compreender - e seguir desvelando - esse nosso mundo social repleto de objetos sociológicos em tempos agudos como nosso presente. Se Bourdieu era considerado por seus colaboradores como um homem "impossível”, pela maneira intensa e rigorosa de trabalho, sua contribuição abre um campo de possibilidades que as novas gerações devem seguir se apropriando para a imersão do conhecimento sobre o mundo social: seguir produzindo uma ambiciosa sociologia da educação!

\section{Referência}

VALLE, Ione Ribeiro; SOULIÉ, Charles (Orgs.). Pierre Bourdieu: uma sociologia ambiciosa da educação. Florianópolis: Editora da UFSC, 2019, 381p.

Recebido em: 09/02/2020 Aprovado em: 15/02/2020

Universidade do Estado de Santa Catarina - UDESC Programa de Pós-Graduação em Educação - PPGE 